\title{
The Genetics of Hereditary Hemihyperplasia in the Achaemenid Era
}

\author{
Hutan Ashrafian ${ }^{1}$, Duncan McHale ${ }^{2}$
}

\section{Institution:}

${ }^{1}$ Institute of Global Health Innovation, The Department of Surgery and Cancer, Imperial College London, 10 ${ }^{\text {th }}$ Floor Queen Elizabeth the Queen Mother (QEQM) Building, St Mary’s Hospital, Praed Street, London, W2 1NY, UK

${ }^{2}$ Clinical Geneticist and Chief Medical Officer, Evelo Biosciences, Cambridge, Massachusetts, MA 02139, USA

\section{Correspondence to:}

Dr Hutan Ashrafian

Institute of Global Health Innovation

The Department of Surgery and Cancer,

Imperial College London,

$10^{\text {th }}$ Floor Queen Elizabeth the Queen Mother (QEQM) Building,

St Mary's Hospital,

Praed Street, London,

W2 1NY, UK

h.ashrafian@imperial.ac.uk 


\begin{abstract}
Background: The first historical description of hemihperplasia through upper limb gigantism was described 2500 years ago. This takes place in the classical era within the context of the ancient Achaemenid dynasty where the emperor Artaxerxes I is described as suffering from arm gigantism.
\end{abstract}

Methods: Pedigree analysis form classical sources

Results: Artaxerxes' family tree demonstrates a powerful pedigree collapse that is comparable with the consanguinity in the historical Spanish Royal line and that of the Hapsburgs. Such an extensive pedigree collapse may therefore offer an explanation for the pronounced phenotype of hemihyperplasia.

Conclusion: The evaluation of ancient evidence with biological and genetic appraisal in presented in this case of hemihyperplasia can offer a deeper understanding of history whilst also highlighting the longstanding impact of genetic diseases on mankind.

Key words: pedigree; collapse; consanguinity; limb; gigantism, genetics; history; hemihyperplasia 
The Achaemenids are a Persian regnal dynasty (550-330 BC) who are commonly credited as spawning the first cohesive world empire and are notorious for their welldocumented battles with the ancient Greeks in the classical era $[1,2]$.

Their transition of power from one ruler to another took place though ruler-designation of one of his male children from several wives (as opposed to primogeniture in many ancient societies). This created a transition volatility that led to some familial intermarriage and occasionally direct dynastic incest (for example by Cambyses II) to bolster legitimacy for some familial lines that was additionally supported by ancient religious texts of the era [2]. This resulted in families with very high degrees of consanguinity at risk of autosomal recessive conditions. In societies where consanguineous marriages between first or second cousins are common there is a doubling of reported congenital malformation rates driven by an increased incidence of recessive conditions [3].

Classical sources typically ascribe the selection of the emperor Artaxerxes I following the political murders of his two elder brothers, the Crown prince Darius and Hystapes. He himself is notable for his unilateral upper limb gigantism (hemihypertrophy) [4]. His 41-year reign (465-424 BC) suggest his investiture to take place in his youth and a likely demise of his elder siblings also in their youths.

Studying the family tree of Artaxerxes I, it can be seen that Artaxerxes I parents were first cousins and as can be clearly seen in Figure 1 there are multiple consanguineous loops in the family. Otanes who is Artaxerxes 1 maternal grandfather is the uncle of his paternal grandmother creating a second common ancestor from whom a 
pathological mutation could have been inherited. Artaxerxes' grandfather Otanes who was concurrently his uncle (by marriage), his biological great uncle and even the father to another child of his grandmother demonstrated the extreme consanguinity present in the family. Figure 1 also highlights the place of a hitherto under-recognised individual Pharnaspes who was documented as a bonafide family member of the Achaemenid clan linking the distinct sub-families of Cyrus the Great and Darius the Great.

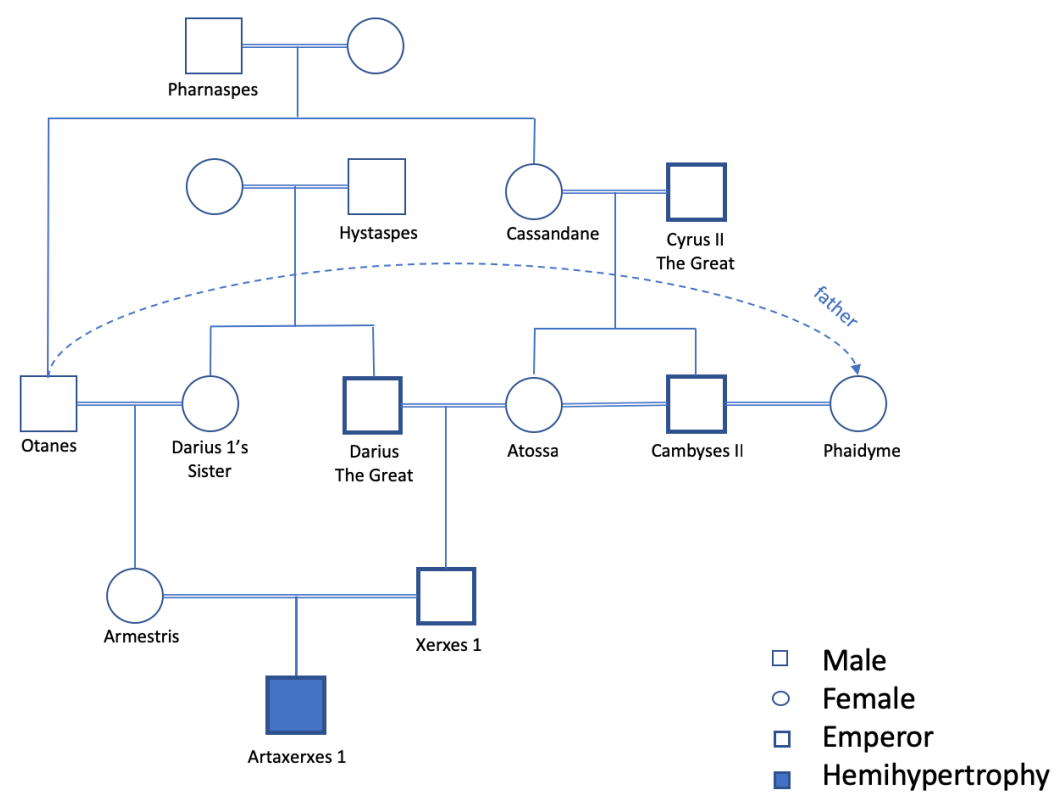

Figure 1. Pedigree chart of the lineage of Artaxerxes I

One way of measuring the degree of consanguinity in a family is to look at the number of direct ancestors within the pedigree. In a non-consanguineous pedigree there would be 2 parents, 4 grandparents and 8 great grandparents and so on. In a consanguineous family these numbers are reduced and this is referred to as pedigree collapse. In Artaxerxes family we can trace back his ancestors 5 generations and we can see that 
there are 8 great great grandparents compared with the expected 16 demonstrating a collapse of 50\% (8/16th) (Figure 2). This is comparable to consanguinity in the Spanish Royal family where King Alfonso XIII of Spain (1886-1941) who also had a 50\% pedigree collapse in his 5 th generation of ancestors. This degree of consanguinity is also comparable to that of the Habsburg line [5,6] famous for the 'Habsburg jaw' [7], where for example the family tree of Charles II had 50\% pedigree collapse in his $6^{\text {th }}$ generations of ancestors $\left(2^{6}=64\right)$ due to only 32 different persons in the 64 positions.

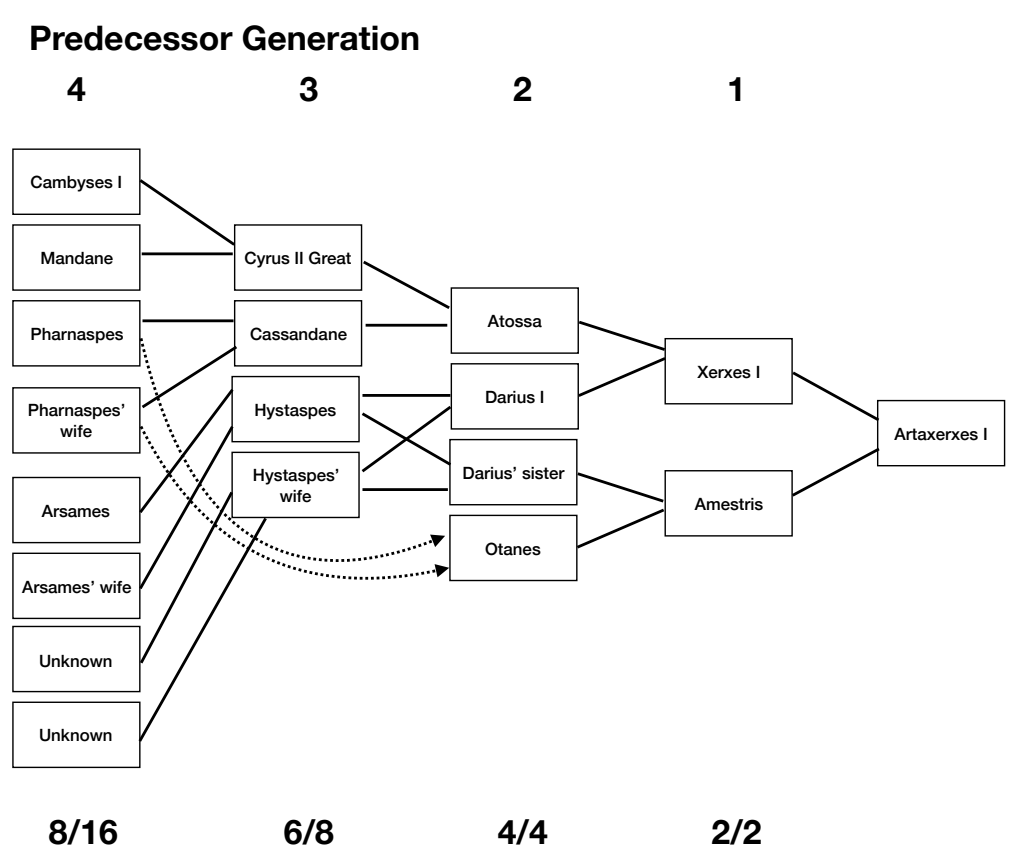

Number of individuals compared to non-consanguinous rates

Figure 2. Pedigree collapse in the line of Artaxerxes I

Such a powerful pedigree collapse may therefore provide an explanation of Artaxerxes' limb gigantism in terms of the increased risk of congenital malformations due to recessive conditions and would accommodate the multiple inherited pathology 
differential that might also explain the early deaths of his male siblings (the female siblings are noted to have lived longer).

The differential diagnoses for hereditary hemihyperplasia, hemihypertropy and 'limb giagantism' (including searches from established genetic databases such as http://omim.org) offers several conditions that would fit the possibility of Artaxerxes successful survival to adulthood with limb gigantism. These include Proteus syndrome, Neurofibromatosis, Blue rubber bleb nevus, Silver-Russel syndrome (S-RS) and Beckwith-Wiedemann syndrome (BWS). Others conditions such as KlippelTrenaunay-Weber syndrome are sporadic and not classically hereditary.

Of these listed conditions, none but the last are inherited as an autosomal recessive trait, and therefore likely to be influenced by consanguinity.

Proteus is due to somatic (i.e. mutations that happen after fertilization) rather than germline mutations. Proteus is not inherited across multiple generations as individuals with heterozygous germline mutations die in-utero. Neurofibromatosis and Blue rubber bleb nevus are autosomal dominant syndromes and conditions with this type of inheritance pattern are not enriched in consanguineous pedigrees. BWS and S-RS have more complex genetic heritability and are conditions derived from imprinting and epigenetic phenomena. S-RS is rarely inherited and is a form of dwarfism so very unlikely to be the cause of Artaxerxes upper limb hypertrophy. Unlike S-RS, BWS is characterized by features of overgrowth including macroglossia, organomegaly and hemihypertrophy and therefore a much more likely candidate. 
BWS is usually the result of an abnormal epigenetic modification or deletion within the epigenetic region on the chromosome 11 imprinted region containing the insulin like growth factor receptor locus and is sporadic in nature with no heritability. This may well be the cause in Artaxerxes' case but the suggestion of minor abnormalities in other family members (for example possible microtia/ anotia in Cyrus the Great's 'large bodied' son Bardiya/ Smerdis) $[2,4,8]$ and the extreme consanguinity in this particular case suggest an inherited form may be the underlying aetiology. BWS is not often inherited but in a small percentage of cases, there are reports of autosomal recessive forms of the syndrome associated with abnormalities of methylation mechanisms which would fit with the consanguineous pedigree $[9,10]$. Genetic analysis has recently suggested that one case was due to a recessive mutation in the mother (germline mutation in NLRP2) resulting in an imprinting defect at multiple loci based on a trans mechanism [11]. As a result, such a finding might also represent the consanguinity effect within a Beckwith-Wiedemann type limb gigantism to match Artaxerxes I's affliction; allowing limb gigantism and a normal life expectancy (not observed in his male siblings who may have died from other consanguinity related disorders). Abnormal methylation at other "imprinted loci" may have led to the early death of his brothers.

The family tree of Artaxerxes I (Figure 1) is derived from Herodotus ('The Father of History') [4] and is controversial due to later historians querying the sources and biases of the author $[12,13]$. These results are however compatible with Herodotus' account where there is clear description of pathology (limb gigantism or possibly hemihypertrophy). It offers a biological explanation for Artaxerxes' ailment through his listed Achaemenid family tree where there now a notable pedigree collapse. Its origins 
highlight the position of Pharnaspes and Otanes (who are less well-known in archaeologically confirmed sources) whose offspring would have contributed to this consanguinity within Artaxerxes' line. One mention of Otanes in archaeology is from the 'Behistun Inscription', which lists his father as 'Thukhra' rather than Pharnaspes [12], although this may represent the same individual whose name has been confused due to ancient language transliteration.

These findings may explain a biological burden that contributed to regnal selection (where the first two royal offspring may have succumbed early due to a combination of inherited disease and politics) rather than one of pure partisan volatility, which has been the predominant explanation to-date. It may also allow the utilization of novel sources, or even re-validate the discerning use of some sources that have been somewhat sidelined (such as Herodotus) $[12,13]$. Subsequent Persian dynasties claimed decent from the Achaemenids, one of which (The Parthians) had familial facial lesions consistent with neurofibromatosis [14] that may also accommodate a diagnosis of limb gigantism. Such a biological and genetic analysis of regnal pedigrees in this fashion may offer additional insights into key events in antiquity to offer a deeper perception and evaluation of history. 
Author contributions

HA: conceptualisation, design analysis, planning, conduct, data analysis, and manuscript preparation

DM: conduct, data analysis, and manuscript preparation

Conflict of interests: The authors declare no conflicts of interest

Ethical statement: As this is a historical analysis of classical literature, IRB appraisal was not necessary in this case

References:

1 Ashrafian H: The Diary of Alexander the Great: A Chronological Retrospect Centred On Arrian's Anabasis Alexandri. London, UK, Institute of Civilisation Press, 2017.

2 Frye RN: The Heritage of Persia. New American Library, 1966.

3 Sheridan E, Wright J, Small N, Corry PC, Oddie S, Whibley C, Petherick ES, Malik T, Pawson N, McKinney PA, Parslow RC: Risk factors for congenital anomaly in a multiethnic birth cohort: an analysis of the Born in Bradford study. Lancet 2013;382:1350-1359.

4 Herodotus, De Selincourt A, Marincola J: The Histories. Penguin Books Limited, 2003.

5 Alvarez G, Ceballos FC: Royal Inbreeding and the Extinction of Lineages of the Habsburg Dynasty. Human heredity 2015;80:62-68.

6 Alvarez G, Ceballos FC, Quinteiro C: The role of inbreeding in the extinction of a European royal dynasty. PloS one 2009;4:e5174.

7 Chudley AE: Genetic landmarks through philately--the Habsburg jaw. Clinical genetics 1998;54:283-284.

8 Schiena S: The False Smerdis: A Detective Story of Ancient Times: The Reconstruction by Ilya Gershevitch. East and West 2008;58:87-106.

9 Viljoen D, Ramesar R: Evidence for paternal imprinting in familial Beckwith-Wiedemann syndrome. Journal of medical genetics 1992;29:221-225. 
10 Wangler MF, An P, Feinberg AP, Province M, Debaun MR: Inheritance pattern of Beckwith-Wiedemann syndrome is heterogeneous in 291 families with an affected proband. American journal of medical genetics Part A 2005;137:16-21.

11 Meyer E, Lim D, Pasha S, Tee LJ, Rahman F, Yates JR, Woods CG, Reik W, Maher ER: Germline mutation in NLRP2 (NALP2) in a familial imprinting disorder (Beckwith-Wiedemann Syndrome). PLoS genetics 2009;5:e1000423. 12 Dandamaev MA: A Political History of the Achaemenid Empire. E.J. Brill, 1989.

13 Henkelman WFM: Cyrus the Persian and Darius the Elamite: a Case of Mistaken Identity; in Rollinger R, Truschnegg B, Bichler R (eds): Herodotus and the Persian Empire. Wiesbaden, Harrassowitz Verlag, 2011, pp 577-634.

14 Ashrafian $\mathrm{H}$ : Limb gigantism, neurofibromatosis and royal heredity in the Ancient World 2500 years ago: Achaemenids and Parthians. Journal of plastic, reconstructive $\&$ aesthetic surgery : JPRAS 2011;64:557. 